\title{
FOSTERING STUDENTS' SCIENTIFIC IMAGINATION IN STEM THROUGH AN ENGINEERING DESIGN PROCESS
}

\author{
Nyet Moi Siew \\ University of Malaysia Sabah, Malaysia \\ E-mail: Snyetmoi@yahoo.com
}

\begin{abstract}
This research was conducted to evaluate the scientific imagination of Grade 10 students from one Malaysian rural secondary school that adopted the integration of the imagination process in an Engineering Design Process (EDPI) through an outreach program in STEM. Three stages of scientific imagination process were evaluated: initiation, dynamic adjustment, and virtual implementation. A total of 50 students aged 16 participated in a 10-hour program, which engaged them in designing and building two different prototypes. Data on students' scientific imagination were captured through a pre-test and post-test, and teachers'field notes based on focus group interviews and observations. The results of paired sample t-tests showed significant differences in all three stages of scientific imagination process, except in the brainstorming of the initiation stage. The findings reveal that students required both personal experience and social or environment interactions in order to progress from the initiation stage to the virtual implementation stage. The findings also suggested that the EDPI approach is able to create a supportive environment for fostering scientific imagination among rural secondary school students.
\end{abstract}

Keywords: engineering design process, scientific imagination, STEM.

\section{Introduction}

Imagination has been regarded as one of the key components of creativity and innovation, and also the source of every form of human achievement (Robinson, 2011). A number of scholars (Pelaprat \& Cole, 2011; White, 1990) claim that individuals who demonstrate a certain degree of imaginative capabilities are considered to be more capable of thinking of lots of possibilities and generating ideas or prototypes that can solve current problems in life. It has been argued that imagination and creativity should be emphasized as important outcomes of science education (Kind \& Kind, 2007). McCormack (2010) voiced support for scientific education as a good way to cultivate talented individuals with rich imaginations and creativity. Fostering scientific imagination in school science lessons can contribute to students' talent development.

Recently, the integration of science subjects (physics, chemistry, biology) and mathematics with technology and engineering (STEM) has gained academic as well as national attention for the purpose of preparing Malaysian students with the skills to meet future scientific and technological challenges and to ensure that Malaysia acquires enough talented workforce in STEM (Ministry of Education Malaysia [MoE], 2014a). Talented STEM individuals have the aptitude to approach and solve problems using their insight, imagination, and ingenuity to create new products. Undeniably the supply of a talented STEM workforce is highly dependent on new entrants into STEM related programmes in upper secondary schools as well as at tertiary levels. However, research has shown that only $45 \%$ of Malaysian students have enrolled in the science stream, and technical and vocational secondary school classes in 2014, which is still far from the ideal ratio of 60:40 (science/technical: arts) policy set in 1967 (MoE, 2014a; Yong \& Phang, 2015). A shortage of talents in areas related to STEM would be a hindrance in gearing Malaysia up to become a developed nation by 2020. Students need exposure to the methods 
PROBLEMS

OF EDUCATION

IN THE $21^{\text {st }}$ CENTURY Vol. 75 , No. 4, 2017

376

employed by those who are already seasoned STEM individuals, who are adept at solving problems by using their imagination to generate ideas to solve everyday problems.

Despite the increased emphasis on fostering children's creativity and imagination in recently introduced Malaysian Primary School Standard Curriculum (MoE, 2014b) and Secondary School Standard Curriculum (MoE, 2016), there is a little evidence to demonstrate research done on scientific imagination among students. Sanders \& Budnik (2009) elaborated the success of camp invention programs in encouraging scientific imagination among elementary students in the STEM disciplines. A study by Liang, Hsu, Huang, and Chen (2012) examined learning environment that stimulates imagination among university students. However, no details were given by those researches as to which learning process might have contributed to the students' scientific imagination. Gajdamaschko (2005), and Porter and Brophy (1988) asserted that hardly any research has been conducted to determine whether imagination can be fostered through science disciplines. Furthermore, there are very few guidelines provided for Malaysian science teachers regarding methods of fostering imagination in STEM education. In contrast, academic research has been extensively conducted on drawing and writing based on the imaginations of artists and novelists (Abdul Majid, Nordin, Kamarodzan, 2015; Salleh, Sailin, 2014).

Weick (2006) stated that imagination is an ability which can be further developed. The literature review thus raises crucial questions: Can scientific imagination be fostered among students? What is the best learning process that encourages the development of scientific imagination among students? A lack of attention to scientific imagination in the design of effective instruction can lead to failure in inspiring creative activities among young school students. Undeniably, the need to fulfil this gap in the learning process is crucial in order for science teachers to determine its effects on students' scientific imagination. The present study addressed this concern by proposing a learning process for Grade 10 students which could foster their scientific imagination in STEM.

The engineering design process model has been identified as a general model of creative process that can be applied in STEM courses (Householder \& Hailey, 2012). In a study conducted locally to evaluate the engineering design process model, it was discovered that rural secondary school students could foster their creativity, problem solving skills, and thinking skills in an outreach challenge program (Siew, Goh, \& Sulaiman, 2016). This finding raises the questions such as "Would students' scientific imagination be fostered as a result of their participation in an engineering design process outreach program?". There is very little evidence to show that this process has been or is being used to foster student's scientific imagination in STEM. Therefore, this research was undertaken to determine whether the engineering design process can contribute to the enhancement of learners' scientific imagination through an outreach program.

\section{Theoretical Framework}

\section{Scientific Imagination}

Imagination is an innate ability in human beings. Scientists use imagination to construct scientific theories and create new inventions to improve life through the process of constant thinking and trial and error (Ho, Wang, \& Cheng, 2013). Thus, great inventions were originated from human imagination. Lindqvist (2003) and Vygotsky (2004) assert that imagination operates based on daily life experiences that inspire creative activities. Likewise, Pelaprat and Cole (2011) regard imagination as a mental activity that links daily life experiences and generates novel ideas. Ho etal. (2013) elaborated this further by stating that imagination is an ability to construct images in the brain that are further concretised and visualised to generate ideas that can solve current problems in life. In tandem, Policastro and Gardner (1999) posit that imagination is an ability that links previous experiences in a unique way to generate thoughts with new meanings and to produce potentially creative thinking. White (1990) similarly opines that to "imagine 
something is to think of it as possibly being so" (p. 184), and that an "imaginative person is one with the ability to think of lots of possibilities, usually with some richness of detail" (p. 185). He elaborated that imagination "is linked to discovery, invention and originality because it is thought about the possible rather than the actual" (p. 186).

According to Wang, Ho, and Cheng (2015), scientific imagination is a mental activity involving the creation of new ideas that are consistent with scientific principles linked to daily life experiences. Wang et al. (2015) classified the process of scientific imagination into three stages: initiation, dynamic adjustment, and virtual implementation (Table 1). Different key components operate during each stage.

Table 1. Stages and components of scientific imagination (Wang et al., 2015).

\begin{tabular}{ll}
\hline Stages & Components \\
\hline Initiation & Brainstorming and Association \\
Dynamic Adjustment & Transformation and Elaboration \\
Virtual Implementation & Conceptualization, Organization, and Formation \\
\hline
\end{tabular}

The initiation stage involves students identifying as many problems as possible (brainstorming). Likewise, students are supposed to find as many relationships as possible among ideas (association). Brainstorming is the process involved in generating an abundance of ideas. Through brainstorming, students can break through any limitations and come up with many problems linked to daily life experiences. The components of brainstorming and association also work in the dynamic adjustment stage in a different way.

During the dynamic adjustment stage, students brainstorm to explore as many possible solutions to the problem and identify relationships among their ideas in order to formulate new ideas for solving problems. This involves the transformation and elaboration component in conferring new meanings on an idea within an associative network in order to transform it into a novel idea. At this stage, students can reorganize the appearance of physical features and functions of creations. The virtual implementation stage involves students to formalize the idea through a detailed sketch. This stage focuses on conceptualization, organization and formation in refining particular ideas and honing students' problem-solving abilities by having them sketch designs, diagrams and models in order to formulate a prototype to be realized in the future. This includes issues related to the choice of materials, techniques for assembling parts, and the means of creating design diagrams and final drafts from the initial diagrams.

Joh, Jaswal, and Keen (2011) have stated that, "The 'imagine' instructions appear to have provided children with a mental problem-solving strategy that was more effective than visual feedback" (p.749). Children naturally enjoy using their imagination to solve problems that arise. Hence, the integration of the three stages of scientific imagination (Wang et al.,2015) into STEM activities could establish a learning atmosphere that encourages imaginations.

\section{Engineering Design Process}

Anumber of researchers (Farmer, Allen, Berland, Crawford, \& Guerra, 2012; Householder \& Hailey, 2012; Hynes, Portsmore, Dare, Milto, Rogers, \& Hammer, 2011) have proposed engineering design process as a means of solving challenges in STEM fields. The Massachusetts Department of Education (2006, p. 84) designed eight steps of the process, which provides a guide for teachers and curriculum coordinators regarding learning, teaching, and assessment in science and technology subjects or engineering specific content from pre-kindergarten to grades 6-8 and throughout high school. Those eight steps of engineering design process include: (1) identifying the need or problem; (2) research on the need or the problem; (3) develop possible 
PROBLEMS

OF EDUCATION

IN THE $21^{\text {st }}$ CENTURY Vol. 75 , No. 4, 2017

378

solution(s); (4) select the best possible solution; (5) construct a prototype; (6) test and evaluate the solution; (7) communicate the solution; and (8) redesign.

Hynes et al. (2011) noted that the engineering design process focuses on solutions and construction of prototypes, which impel students to encounter the process of creative and critical thinking as well as problem solving skills. An affiliated research conducted in Malaysia showed improvement in creativity, problem solving skills, and thinking skills among rural secondary school students in the Engineering Design Process outreach challenge program (Siew, Goh, Sulaiman, 2016). Hence, this process is proven to be able to offer an effective route as an instructional framework for fostering scientific imagination, which can be carried out among rural secondary school students.

This study attempts to investigate whether scientific imagination can be fostered among Grade 10 Science Stream students using a proposed engineering design process with imagination model (Figure 1). The scientific imagination process as proposed by Wang et al. (2015) is integrated into the engineering design process model in order to accommodate the development of scientific imagination among students. Some minor changes were made to the last three stages of the original model proposed by the Massachusetts Department of Education. This was done to ensure that students could produce physical prototypes that make best use of their scientific imagination, materials and time provided.

The advantages of the proposed seven steps of the engineering design process is that it focuses on brainstorming and association in identifying and researching of problems and solutions that drive students to encounter the process of initiation. It allows students to become aware of the many possible solutions as they engage in sketching to propose solutions. The process of finding the optimal solution by designing a prototype based on constraints in time and materials requires participants to engage in transformation and elaboration. Students are required to communicate their solutions to facilitators and peers on how to formalize the idea to be realized before the final construction, testing and evaluation stage, thus driving them into the conceptualization, organization, and formation. By going through the seven stages in this process, learners are intended to develop scientific imagination while carrying out the STEM activities.

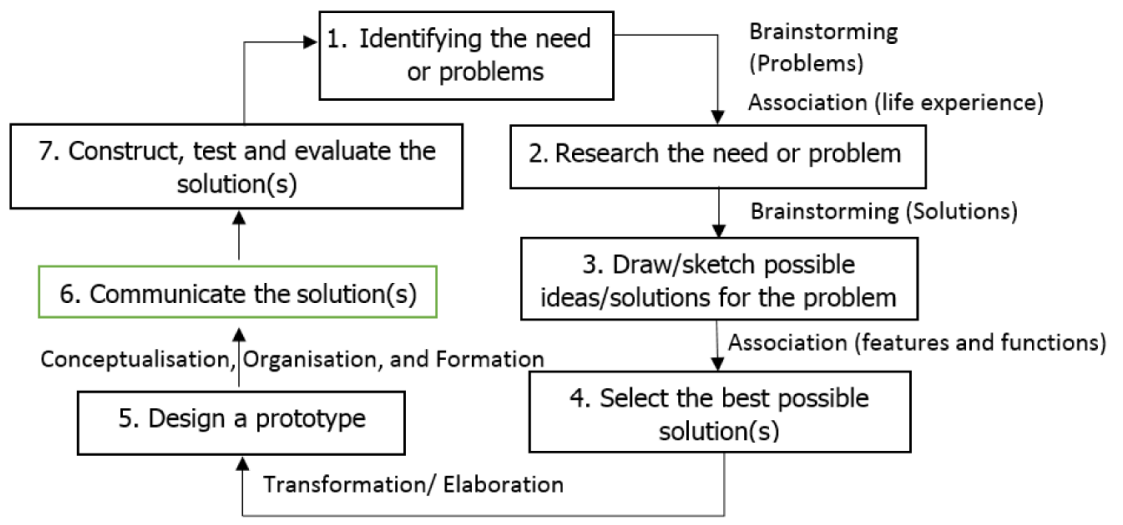

Figure 1: The proposed engineering design process with imagination model.

\section{Research Purpose and Research Questions}

Relatively few studies have been conducted on the fostering of secondary students' scientific imagination through the employment of the engineering design process. This research was therefore undertaken to explore if the integration of imagination process in an engineering design process (EDPI) and its possibilities in fostering the scientific imagination of rural secondary school students (16 years old) vis-á-vis an outreach program in STEM. Its secondary 
aim was to examine the scientific imagination process that students encounter while engaging in EDPI activities. Additionally, this research was also aimed to examine some of the students' thoughts or issues while engaging in the generation of ideas. The scientific imagination in this study refers to each student' individual mental activity to generate novel ideas through processes as classified by Wang et al. (2015): initiation, dynamic adjustment, and virtual implementation. Accordingly, the research questions guiding this research were:

1. Is there a significant difference between the pre- and post- test mean scores in scientific imagination among students as a result of their participation in the EDPI outreach program?

2. What are the scientific imagination processes that students encounter while engaging in EDPI activities?

3. What are the students' thoughts or issues raised while being engaged in generating ideas during the EDPI activities?

\section{Methodology of Research}

\section{Research Design and Participants}

A single group with intervening EDPI outreach program design was carried out in this research. A mixed method research design combining both quantitative and qualitative approaches at the data collection and interpretation phase was used to strengthen the knowledge claim of the research (Creswell, 2012, p. 540).

On April 2016, the outreach program was conducted in one randomly assigned secondary rural school. The selected school is located within the Interior Division of Sabah, Malaysia. The school is located about 130 kilometres from Kota Kinabalu. The participants consisted of 50 Grade 10 Science Stream students with 37 females (74\%) and 13 males (26\%) aged 16 years old. In the Malaysian schooling system, students from the age of 16 have the opportunity to pursue two years of study in the upper secondary upon completion of the lower secondary education. Students who are academically inclined can choose between two main streams: Science or Arts. Seemingly, the Science Stream students are perceived to be more adept at performing in mathematics and science related subjects. Thus, purposive sampling was employed in the selection of the participants. According to Fraenkel and Wallen (2000), purposive sampling minimizes experimental contamination. Selection of Grade 10 Science Stream students from one school who possessed knowledge, ideas, life experience or experiences of STEM relevant to the research would best help the researcher understand the research question (Creswell, 2003).

Students were gathered into heterogeneous groups of four to five members on the basis of random selection in accordance with gender and ethnicity (diversity). The groups were assigned by the teacher so that there would be an inclusion of students of high-, mediumand low competency levels based on their individual scores achieved in the end-of-semester examination.

A total of 33 science teachers participated as assessors and facilitators in EDPI outreach program. They were trained to carry out the facilitation and assessment prior to the program. They stood of qualified science teachers with degrees in Science Education and obtained passing grades in the Research Methodology course (qualitative and quantitative) in their Masters course which they were undertaking at the time. Nine of these teachers helped the researcher to develop the STEM activities and testing procedures. The researcher guided the science teachers on how to facilitate students according to the seven steps of the engineering design process and scientific imagination in order to ensure the consistency and reliability in the implementation of the EDPI activities across students. 
Nyet Moi SIEW. Fostering students' scientific imagination in STEM through an engineering design process

PROBLEMS

OF EDUCATION

IN THE $21^{\text {st }}$ CENTURY Vol. 75 , No. 4, 2017

380

\section{Ethical Considerations}

Permission to do the research was obtained from the school principals and teachers. At the beginning of the program, participants were presented with a letter of consent detailing the nature of their involvement in the program and the need to provide their consent on the sheet indicating their full understanding. The purpose of the research was explained in detail and all the participants were assured of the confidentiality of their response and of complete anonymity. Therefore, no names of the participating students were used in reporting the findings. All participants were informed that anyone could withdraw from the program and the interview without penalty. Code names were used for the data to ensure the confidentiality of the schools and individual identities.

\section{Data Collection}

The research data were collected through multiple qualitative and quantitative means: participants' responses to open-ended questions in scientific imagination pre-test and post-test, and teachers' field notes. The pre-test and post-test measured student's scientific imagination in terms of initiation, dynamic adjustment, and virtual implementation shifts over the duration of the program. Teachers made field notes based on their observation during the STEM activities, and the focus group interviews with students. A total of 10 semi-structured focus group interviews were carried out after the completion of each STEM activity. The interview questions were open-ended (Table 2) and the students were encouraged explicitly to draw their answers from their learning experiences of generating ideas during the EDPI activities. Each focus group interview was conducted in groups consisting of 4-5 students. Table 2 shows the tools that were used to address the corresponding research questions. Likewise, focus group observations were collected using an observation form adopted from scoring guides developed by Wang et al. (2015). The quality of the students' responses was ranked from " 0 " (Level 0 : the lowest level) to "3" (Level 3: the highest level).

\section{Table 2. Data capturing tools.}

\begin{tabular}{|c|c|}
\hline $\begin{array}{l}\text { Research Questions } \\
\text { Is there a significant difference between the pre-test and post- test mean scores in sci- } \\
\text { entific imagination among students as a result of their participation in the EDPI outreach } \\
\text { program? }\end{array}$ & $\begin{array}{l}\text { Data Capturing Tools } \\
\text { Scientific Imagination } \\
\text { pre-test and post-test }\end{array}$ \\
\hline $\begin{array}{l}\text { What are the scientific imagination processes that students encounter while engaging in } \\
\text { the EDPI activities? }\end{array}$ & $\begin{array}{l}\text { Teachers' field notes } \\
\text { based on focus group } \\
\text { observations }\end{array}$ \\
\hline $\begin{array}{l}\text { 3. What are the students' thoughts or issues raised while being engaged in generating } \\
\text { ideas during the EDPI activities? } \\
\text { a) How do students think of ideas for the problems/solutions? } \\
\text { b) What kinds of difficulties did students encounter during the process of thinking for } \\
\text { ideas? How did students overcome these difficulties? } \\
\text { c) How do students assemble the ideas in order to produce the final prototype? Are there } \\
\text { any differences between the final prototype and the oriainal ideas? Why? }\end{array}$ & $\begin{array}{l}\text { Teachers' field notes } \\
\text { based on focus group } \\
\text { interviews }\end{array}$ \\
\hline
\end{tabular}

This scheme enabled the researcher to identify and gain knowledge about scientific imagination which students encountered during the STEM activity. 


\section{Instrument}

The 4-item scientific imagination test was designed, developed and adapted based on the Scientific Imagination Verbal Test designed by Wang et al. (2015). It is an open-ended situationbased test that measures students' scientific imagination. The scientific imagination test covered the four key components of scientific imagination processes: brainstorming, association, transformation and elaboration, and conceptualization, organization, and formation.

Three experts who each specializes in creativity, science education, and educational assessment were invited to review the item contents according to the components of scientific imagination. The items were revised according to suggestions from these experts. The topic of the test entailed the El Niño phenomenon which occurred in the country and the ensuing difficulties affecting a local village. This includes problems in acquiring clean water and electricity due to the failure of the only mini-hydroelectric station because the river had become shallow. In this open-ended test, students were required to complete two missions. The first mission (Mission 1) consisted of three questions. The first question required the participants to first identify the potential problems brought up by the El Niño phenomenon. The second question (Question 2) required students to identify the specific problems encountered by the villagers, which incidentally, is linked to the students' own life experiences. The two components associated with these questions were brainstorming and association. The third question required the participants to propose solutions to the identified specific problem. The main components included in the third question were transformation and elaboration. Students were instructed to include descriptions and illustrations in their answers, as well as operating instructions for their solution. A time frame of 10 minutes was given to complete the first mission.

Following successful completion of the first mission (answering the first three questions), the students were given a second mission (Mission 2), in which they had to draw one "new invention" to solve the specific problem identified by Question 2 in the first mission. Time was also limited to 10 minutes for this portion of the test. In Mission 2, only the conceptualization, organization, and formation component was assessed.

Since English is not commonly used by the participants, the researcher translated the instrument into the Malay language; which was reviewed by a professional Malay language teacher. A pilot study was conducted in the form of a three-hour program to address one situation-based problem. A total of 30 Grade 10 rural secondary school students (16 years old) took part in the pilot study. Students completed the tests before and after the program. They were also asked to comment on the readability of the items and to make suggestions regarding the items in scientific imagination test. They agreed that all items were relevant, thus should remain in the final test.

Items were analysed using WINSTEPS (Linacre, 2003) based on the Rasch measurement model to assess the suitability of items. The four dimensions of scientific imagination were analysed using partial credit model proposed by Bond and Fox (2015). Analysis of fit helps detect discrepancies between the Rasch model expectation and the data collected (Linacre \& Wright 2012). Unidimensionality assumes that all items measure a single ability (Bond \& Fox 2015). The principal component analysis of residuals (PCAR) was used to identify the second factor that may become a threat to unidimensionality assumption. Item reliability index is the estimation of replicability of item placement within a hierarchy of items along the measured variable if these same items are to be given to another sample of comparable ability. Item separation is used to verify the item hierarchy.

All items showed point-measure correlations (PTMEA Corr.) range from 0.27 to 0.81 . A positive index indicates that all the items move in one direction and measure scientific imagination (Bond \& Fox, 2015). The infit and outfit mean squares range for all the items was within 0.60 to 1.40, which are in the acceptable range (Bond \& Fox, 2015). Based on the PCAR analysis, the raw variance explained by measures is $45.2 \%$ and Eigen value for unexplained 
Nyet Moi SIEW. Fostering students' scientific imagination in STEM through an engineering design process

PROBLEMS

OF EDUCATION

IN THE $21^{\text {st }}$ CENTURY Vol. 75 , No. 4, 2017

382

variance in first contrast is 1.8 , indicating that the items in measuring scientific imagination are probably unidimensional (Linacre, 2003). The item separation and reliability was found to be 3.27 and 0.91 respectively. An item reliability of more than 0.90 implies that the item can be separated into four stratas (very easy, easy, difficult and very difficult) (Linacre \& Wright, 2012) in measuring scientific imagination of Grade 10 students.

\section{Data Analysis}

Analysis of Students' Level of Scientific Imagination

Scoring procedures. The students' scientific Imagination was scored using criteria adapted from scoring guides developed by Wang et al. (2015) and partial credit model proposed by Bond and Fox (2015). By analysing students' answers in test items, the brainstorming, association, transformation and elaboration, and conceptualization, organization, and formation components were evaluated. Table 3 shows the scoring criteria used for assessing the scientific imagination.

Table 3. Scoring criteria for scientific imagination.

\begin{tabular}{|c|c|c|c|}
\hline Item & Components & Scoring criteria & Score awarded \\
\hline 1 & Brainstorming & $\begin{array}{l}\text { Number of relevant problems } \\
\text { specified from the situation }\end{array}$ & $\begin{array}{l}\text { '0' point = irrelevant problem } \\
\text { '1' point = } 1 \text { to } 4 \text { relevant problems } \\
\text { '2' points }=5 \text { to } 8 \text { relevant problems } \\
\text { '3' points }=9 \text { to } 12 \text { relevant problems }\end{array}$ \\
\hline 2 & Association & $\begin{array}{l}\text { Number of relevant problems } \\
\text { which is correlated with the life } \\
\text { experiences of students as part } \\
\text { of occupants }\end{array}$ & $\begin{array}{l}\text { '0' point = irrelevant problem } \\
\text { '1' point }=1 \text { relevant problem } \\
\text { '2' points }=2 \text { relevant problems } \\
\text { '3' points }=3 \text { or greater than } 3 \text { relevant prob- } \\
\text { lems }\end{array}$ \\
\hline 3 & $\begin{array}{l}\text { Transformation } \\
\text { and elaboration }\end{array}$ & $\begin{array}{l}\text { Number of relevant solutions } \\
\text { which illustrate the physical } \\
\text { features and functions }\end{array}$ & $\begin{array}{l}\text { '0' point = irrelevant solution } \\
\text { ' } 1 \text { ' point }=1 \text { relevant solution } \\
\text { '2' points }=2 \text { relevant solutions } \\
\text { '3' points }=3 \text { or greater than } 3 \text { relevant solutions }\end{array}$ \\
\hline 4 & $\begin{array}{l}\text { Conceptualiza- } \\
\text { tion, organization, } \\
\text { and formation }\end{array}$ & $\begin{array}{l}\text { A detailed sketch of prototypes, } \\
\text { which include an illustration of } \\
\text { the choice of material, operation } \\
\text { and techniques for assembling } \\
\text { parts }\end{array}$ & $\begin{array}{l}\text { '0' point = irrelevant sketch of prototype } \\
\text { '1' point = a rough sketch of prototype } \\
\text { '2' points = a fairly detailed sketch of prototype } \\
\text { '3' points = a very detailed sketch of prototype }\end{array}$ \\
\hline
\end{tabular}

Inter-rater reliability. Due to subjectivity in the scoring criteria, it was deemed necessary for an independent person to interpret the students' answers using the same scoring system. A total of 20 randomly chosen answer scripts (each from the pre-test and post-test) were rated independently by a science teacher together with the researcher. Prior to this, both score raters attended a training in scoring for the Scientific Imagination. Before scoring, each rater examined 20 students' answers independently by following the scoring criteria given in Table 2. Disagreements in scoring the students' answers were resolved through a discussion between the raters. The Pearson product-moment correlation coefficients between the two sets of scores in the pre-test and post-test were computed. Correlations between scores varied between 0.78 to 0.98 . The results suggest that the scoring procedure was reliable. 


\section{Analysis of Quantitative Data}

For the quantitative data, the difference in the mean scores for each component between the pre- and post-test was computed as a measure of change in the participants' scientific imagination. The paired sample t-test was conducted to compare the mean scores of the pre-test and post-test to determine whether there existed significant difference in scientific imagination.

\section{Analysis of Qualitative Data}

The qualitative data was analysed through thematic analysis. Thematic analysis is a form of a pattern recognition technique by searching through the data for emerging themes (Fereday $\&$ Muir-Cochrane, 2006). Two researchers independently reviewed the teachers' field notes by reading the data line by line and identified recurring patterns in the data. The patterns identified by each researcher were compared to ensure the validity of the codes. The researchers dealt with codes which had no consensus by comparing and contrasting perspectives and concerns in order to create common codes. Through multiple reviews and an iterative process, categories and codes were refined and grouped into themes.

\section{Learning through EDPI Outreach Program}

The EDPI outreach program was designed with a focus to encourage rural school students to solve a situation-based problem by utilizing the engineering design process with the imagination model (Figure 1). Through this endeavour, students were conditioned to engage in a myriad of brain-stimulating and integrative activities: to identify problems, to think about solutions, to design, to sketch, to communicate and to construct a physical prototype of their design.

The EDPI program consisted of two STEM activities, lasting about 5 hours each. The STEM Activity 1 dealt with the El Niño phenomenon and its effects on crops, the environment and humanity. In context, Malaysia was first hit by El Niño in 1998 and was recently impacted by the phenomenon again. The scenario is described as below.

From the end of 2015 to this present day, agricultural activities in the Tambunan district has suffered adverse effects caused by El Niño. The prolonged drought has troubled farmers as well as students.

The STEM Activity 2 dealt with poor irrigation in paddy plantation as well as low rice produce in a rural area in Sabah. The purpose in exposing this activity was to engage students to make use of alternative energy and technology to improve the irrigation and output of farming activities. The scenario is described as below.

The Tambunan district is a high ground area in the interior of Sabah and its paddy fields comprise 1,445 hectares of the district. There are two main rivers that give the paddy fields their main source of water; they are the Tondulu and Tambatu Rivers. Nevertheless, farmers are increasingly facing the problem of water supply and increasing their crops for commercial and personal use.

These STEM activities were introduced to accommodate the specific context of the students' daily lives in order for them to foster their imagination and understanding of STEM concepts. The students carried out the seven steps of the proposed engineering design process with the imagination learning model (Figure 1) which are described as below. 
Nyet Moi SIEW. Fostering students' scientific imagination in STEM through an engineering design process

PROBLEMS

OF EDUCATION

IN THE $21^{\text {st }}$ CENTURY Vol. 75 , No. 4, 2017

384

Initiation (Brainstorming, Association)

Step 1: Identified Problems

- Students brainstormed together as many problems that were likely to arise by deriving them from the given scenario.

Step 2: Associated or Correlated Problems

- Students associated or correlated as many problems as possible with their life experiences.

- Students then identified the main problems encountered in their daily lives.

Dynamic Adjustment (Transformation and Elaboration)

Step 3: Developed Possible Solutions

- Students brainstormed in groups using their imagination to propose as many possible solutions to the problem.

Step 4: Selected the Best Possible Solutions

- Students deliberated and chose the most suitable physical features and functions for possible creations to solve the pressing issue.

Step 5: Designed a Prototype

- Students transferred their ideas into sketches.

Step 6: Communicated the Solutions

- Students elaborated the physical features and functions of their models to their facilitators. The students were expected to showcase the science and mathematical concepts exhibited in their designs or prototypes.

Virtual Implementation (Conceptualization, organization, and formation)

Step 7: Reorganization

- From the facilitator's comments, students reorganized and refined their previous prototypes by including the details of improved choice of material, techniques for assembling parts, and the means to create their prototypes. Students gave a name to their creations.

Step 8: Prototype Creation and Evaluation

-Students then created a physical prototype based on the final drafts of their design. Finally, they demonstrated and explained their final product to their peers and facilitators for feedback.

The role of the teachers was to guide their students to come up with their own solutions. Teachers offered assistance when the students became dispirited, but did not suggest solutions for them. Through guided discussions and the engineering design process, it was intended for the students to develop scientific imagination which can be applied in the science, mathematics, engineering, and technology fields.

\section{Results of Research}

\section{Quantitative Analysis}

A paired sample t-test was performed to determine whether there were any significant differences between the pre-test and post-test mean scores in the components of scientific imagination. The result of this analysis (Table 4) indicates that the students' post-test mean score $\left(\mathrm{M}_{\mathrm{A}}=1.64, \mathrm{M}_{\mathrm{TE}}=2.52, \mathrm{M}_{\mathrm{COF}}=2.83\right.$ respectively $)$ was significantly higher than their pre- 
Table 4. Paired sample t-test for the components of scientific imagination.

\begin{tabular}{|c|c|c|c|c|c|c|c|c|}
\hline \multirow[t]{2}{*}{ Stages } & \multirow[t]{2}{*}{ Components } & \multicolumn{2}{|c|}{$\begin{array}{l}\text { Pre-test } \\
(\mathrm{N}=50)\end{array}$} & \multicolumn{2}{|c|}{$\begin{array}{l}\text { Post-test } \\
(N=50)\end{array}$} & \multirow[t]{2}{*}{$t$} & \multirow[t]{2}{*}{ df } & \multirow[t]{2}{*}{$p$} \\
\hline & & Mean & SD & Mean & SD & & & \\
\hline \multirow[t]{2}{*}{ Initiation } & Brainstorming (B) & 1.88 & .59 & 2.00 & 0.70 & 1.14 & 49 & .26 \\
\hline & Association (A) & 1.02 & .47 & 1.64 & .80 & 5.13 & 49 & $p<.05$ \\
\hline $\begin{array}{l}\text { Dynamic Adjust- } \\
\text { ment }\end{array}$ & $\begin{array}{l}\text { Transformation \& } \\
\text { Elaboration (TE) }\end{array}$ & 1.68 & 1.00 & 2.52 & .65 & 5.49 & 49 & $p<.05$ \\
\hline $\begin{array}{l}\text { Virtual Implementa- } \\
\text { tion }\end{array}$ & $\begin{array}{l}\text { Conceptualization, } \\
\text { Organization, \& } \\
\text { Formation (COF) }\end{array}$ & 1.60 & .90 & 2.828 & .44 & 8.49 & 49 & $p<.05$ \\
\hline
\end{tabular}

Note: Significant level at $\mathrm{p}=.05$

\section{Qualitative Analysis on Participants' Response - Teachers' Observation}

The science teachers' field notes which were based on focus group observations was analysed using thematic analysis. The abbreviations used for the analysis were "S" represents Student, and ' $G$ ' represents Group. The scientific imagination process which students encountered while engaging in STEM activities is described as below.

Initiation of Problems - Brainstorming

Specifying the problems based on real life situations. The facilitators expressed that most of the participants could brainstorm and specify many problems inflicted by El Niño and poor irrigation in the paddy field. Most groups used mind maps to brainstorm the problems. The problems suggested by the students were the decrease produce of rice, water shortage in paddy fields, infertile crops, limited outdoor activities, risk of diseases, arid ground, affected emotions, fire outbreaks, and heat stroke. Several groups even expressed their concerns about the level of water in the rivers due to over-vaporization.

Initiation of Problems - Association

Specifying problems which correlate with daily life experiences. The facilitators expressed that their students could make links to own personal daily experiences. Additionally, they had hands-on experience seeing and handling the planting of paddy. Students also shared real life encounters where their families faced farming issues such as lack of rain water which causes low rice and ginger produce, dehydration during sports activities, health maladies such as headaches and migraines, increase of electrical bills, and forest fires causing haze. Students added that the extreme hot weather caused fatigue and disrupted their daily work. 
Nyet Moi SIEW. Fostering students' scientific imagination in STEM through an engineering design process

PROBLEMS

OF EDUCATION

IN THE $21^{\text {st }}$ CENTURY Vol. 75 , No. 4, 2017

386 Initiation of Solutions - Brainstorming

Proposing solutions to the problem. Overall, all the groups managed to generate many solutions to overcome the problems specified by group members. The students decided to create wind mills, water mills or water pumps to solve the problem of water shortage in paddy fields. The idea of making a wind mill was for the purpose of producing electricity as an energy source while the water pump idea was to enable water to flow systematically in big quantities. Water mills function by creating a strong force that pushes water to flow in bigger quantities to enter into paddy fields. The prototypes were proposed based on the students' observations of paddy fields in their surroundings. The participants explained that adding wind mills could help generate electricity because the villages were located far from the source of electricity. This showed that the students took the villagers' welfare into account since they were able to envision the villagers enjoying the use of electricity without worrying about bills.

The most common examples used by many groups to battle the extreme heat caused by El Niño was the greenhouse, which incorporates the use of solar panels to generate electricity as well as a water tank to collect rain water which circulates it to the whole house. Another solution propounded was a water sprinkler to help water plants, which could save villagers energy as well as cost since it is built using only recycled materials. Students also derived their ideas from something they had seen before:

"We created this model based on our observation in several places that have wind mills. We tried to manipulate that idea into something new with more functions that can positively impact the community". (S3, S4, G2).

Collectively, the majority of the students considered their families when deciding on a solution for the problems they faced caused by El Niño.

\section{Initiation of Solutions - Association}

Illustrating the physical features and functions of their creations. From the science teachers' observation, most groups could illustrate the physical features and functions of their creations per suitable science and technology concepts, while some groups expressed problems they faced concerning materials and technical issues. For example, Group 1 and 2 facilitators stated that their students initially had difficulty and took some time to illustrate ways to to combine the function of the wind mill with the water pump. Nonetheless, students eventually managed to assemble their creation through Sketch 1 and Sketch 2, after the facilitator guided them through relevant questions such as, "What alternative energy can generate electricity?" and "How can the wind mill power up the water pump?".

Group 10 was a shining example in the activity. They unanimously decided to create a water mill because they had witnessed farmers using this contraption in the process of planting paddy. This group truly impressed their facilitators and showed great enthusiasm in the activity. Comparatively, Group 8 students had to receive lots of encouragement and feedback from their facilitators to illustrate their models. They had never seen a water pump before so this made it difficult for them to envision and draw one. The facilitator described how to make a water pump by relating it with the functions of the human respiratory organs such as the diaphragm and heart. Consequently, this group realized that the creation of the pump was directly influenced by the observation of the way those human organs work. This group could illustrate their model anyway by applying the use of valves to create a singular flow and observing low pressured spaces to contain water using the concept of breathing.

Group 8 subsequently illustrated their idea by proposing a prototype named 'El Niño Water Fountain' that used the vaporization technique and an air filter tool. They also stated 
that the creation could collect water from plant sources such as bamboo and by digging up the

ground to search for water.

Dynamic Adjustment -Transformation and Elaboration

Reorganize or refine the physical features and functions of the creations to solve the problem given. Facilitators stated that most of the groups could reorganize or refine their models as they progressed from Sketch 1 to Sketch 3. More elaboration on physical features and functions were observed in students' sketches. There were two groups that retained some of their original ideas from the first sketch while most groups transformed the specifications of their sketches from the ground up. Sketches from one group had only slight changes in the three sketches they were asked to do.

One example of a good sketch was created by Group 7. At first, they drew a simple sketch that matched the real prototype they had wished to create. They drew a newer sketch that was more detailed through their own effort and good planning and creatively named their creation the 'Non Stop Water Resources System'. Other groups, such as Group 4 managed to include the process of creating their models in their sketches.

Initially, Group 9 presented very simple and basic sketches of their models. They were very much influenced by their childhood experiences. They explained that they used to eat chocolates that had fan blades to play with. Others shared that they had seen wind mills in paddy fields that had whistles attached to them to scare off birds. After discussing and drawing a few sketches, they drew a more sophisticated model together with the specifications of its parts.

Participants from Group 5 and 6 underwent a different experience compared to the other groups. They were reported to have made unclear and weak sketches especially in arranging the physical characteristics to create their model. The students were simply perplexed with the use of recycled materials. The facilitators reported that while presenting their creation, the students showed poor knowledge about scientific concepts such as the greenhouse effect, renewable energy and heat convection. Nevertheless, they could explain two physical traits that influenced the wind mill's ability to spin well which were the size and number of blades on the wind mill. The facilitators took note that the students did not create a wind mill that could generate a large amount of electrical current. So, the facilitators gave them guidance by directing them to questions about Green Technology which eventually set the path for their creation.

\section{Virtual Implementation (Conceptualization, Organization, and Formation)}

Facilitators stated that all of the students could draw their final drafts but they vary in details, focus, characteristics, choice of material, and techniques for assembling parts. Some sketches were elaborated and clearly demonstrated the functions of the models while others were too simplistic and lacking in detail and sophistication. Overall, the groups made improvisations to the ideas for the model from the materials they used while assembling their sketches.

It was difficult for a few groups to determine an idea to draw for their best sketches. This involved the process of choosing the right material, assembly techniques for the parts of the prototype and the steps to create the final draft of their sketches. These groups needed time to conceptualize their ideas unto the sketch through the process of constant thinking and trial and error. A student stated about drawing sketches,

"This activity stimulated me to think far and I got to think of many ideas and sketches. We used the trial and error method to draw the most suitable sketches" (S2, G7).

There were groups that were able to create organized and precise second sketches compared to their first ones. Several participants could draw well by labelling the parts of their creation. Improvisations were done in some of the group sketches particularly in rearranging 
Nyet Moi SIEW. Fostering students' scientific imagination in STEM through an engineering design process

PROBLEMS

OF EDUCATION

IN THE $21^{\text {st }}$ CENTURY Vol. 75, No. 4, 2017

388

and adding to the physical characteristics and functions of the models' parts. Other sketches showed the combination of materials, assembly techniques and steps to create the prototype. The facilitators often played a role in improving the student's sketches. They would challenge their students with questions in order to get the participants to create better and more effective creations.

Group 10 did not initially sketch a water tank and irrigation pump but after testing the prototype out and establishing its weakness, they felt the need to add a water tank and irrigation pump to enable the model to function better. They also improvised the water mill so that it would not only increase irrigation but also generate electricity.

On the other hand, group 3, 4, 7 and 10 facilitators were satisfied with their student's efforts to refine their creations. They commented that their groups had drawn detailed sketches which showed the good combination of various materials, installation techniques and methods of creating their model. The students drew their sketches along with the physical traits of their creation such as the fan, wires, and motor. A Group 7 student remarked that,

"The new thing we have learned is the combination of wind mill and the water pump. Before this, we know that the wind mill functions to generate electricity only, but now we know that the wind mill can be connected to the water pump. The electricity produced by wind mill is used to power up water pump, thus can overcome the problem of water shortage" (S3, G7).

An example of the students' efforts to create a prototype was by creating more than one possible model using different materials. Group 1 did a good job sketching two designs for their model. They described the use of a drink can, $1.5 \mathrm{ml}$ plastic bottles, bottle caps, DC-motors, electrical wires, and hot glue gun. The students created two wind mills each from a $500 \mathrm{ml}$ bottle and drink can each. They realized that the aluminum wind mill could generate more energy so they made more adjustments to this creation to increase its energy flow. Group 9 created very basic and simple drawings of their creation in the beginning but after brainstorming, they took stability into account to create a wind mill that had a bigger base to increase its stability. The students improvised their ideas and sketches as they went along this process. A student remarked,

"There were many differences. Among them, our first idea until the right product because from the beginning we identified the weaknesses and every stage we improved it till we got a model like this that has many functions because we combined many elements. For example, using water and also solar" (S4, G9).

The statement such as above demonstrates that the students constantly made improvisations in the choice of material and assembly technique to create a more stable and neater prototype.

\section{Qualitative Analysis on Participants'Responses - Focus Group Interview}

The science teachers' field notes which were based on focus group interviews was analyzed using thematic analysis. The students' analyzed responses were about their thoughts or issues they faced while engaging in generating ideas during the STEM activities. The main findings in relation to the sources of generating ideas, difficulties encountered and ways to overcome these difficulties, and ways to assemble the ideas for producing the final prototypes are discussed as below:

\section{The Sources of Generating Ideas}

A majority of the students from almost all of the 10 groups stated that their own past daily life experiences inspired them in generating ideas to solve the issue. This was gained via their observations and experiences of their surroundings and the environment in the paddy fields and 
during El Niño. A significant number of students said that their ideas derived from television shows, internet videos, blogs, social media platforms or previous school experiments. Besides that, some groups expressed that group discussions were the catalyst for their ideas while three groups stated that they had thought of ideas based on their own knowledge or views. Even the facilitators' questions helped the students to think of ideas. Other ways which students thought of new ideas were through the combination of their ideas as well as through the trial and error method. Some students said that ideas were derived from their own imagination while another two said they improvised ideas that had already existed.

\section{Difficulties the Students Encountered during the Process of Thinking of Ideas and Ways They Overcame these Difficulties}

Most groups revealed that participating in the STEM activities was a new experience and that they had insufficient scientific and technical knowledge to think of novel ideas. This was evident in their individual sketches in the scientific imagination pre-test where they used irrelevant scientific concepts to elaborate the mechanism of their inventions. It was also noted that students chose the irrelevant materials and assembly techniques for the prototypes' parts. Some groups commented that the time given to think of new ideas was insufficient.

A majority of the students stated that they overcame these difficulties by seeking helps from their own group members. Group members combined and refined their group members' ideas in order to get the best solution. They used the provided materials to explain their ideas to one another, while others received guidance, support or inspiration to voice ideas.

Others sought help from the facilitators. The most notable assistance provided by the facilitators, according to them was in the form of clues, ideas or tips and encouragement to boost their morale. Some students independently solved the problem by employing their skills learned in the science process, experimented with methods or derived solutions from scientific investigation they had learned in school.

\section{Methods for Assembling Ideas in Order to Produce the Final Prototype}

Most of the students admitted that their final product and original idea were very different from one another while two groups said there were slight differences between their initial idea and final product. This was due to the fact that students had combined many elements together. The students mainly assembled their ideas by examining the most suitable and best idea among them. Through discussions, students combined their original idea with the final sketch to create the prototype. They tested their prototypes through many attempts, improved or modified their original idea through the process of constant thinking and trial and error. Other students stated that their ideas were gained during the sketching process and creating the prototype. Two groups said that by just observing their materials they were able to come up with ideas.

\section{Discussion}

The research findings revealed significant statistical gains in the participants' scientific imagination while participating in the EDPI outreach program. The EDPI approach, which focused on the integration of imagination in the engineering design process was proven to promote significantly positive changes within the stages of association, dynamic adjustment, and virtual implementation.

Research findings also showed that students were inclined to associate their daily life experiences with the environmental and agricultural problems presented in the activities. Conclusively, the findings reinforced previous studies (Lottero-Perdue, 2015; Neo, Neo \& Tan, 2012) which claim that the engineering design process provided a mechanism through which students learn to make connections by engaging in 'real-world' contexts. This research 
PROBLEMS

OF EDUCATION

IN THE $21^{\text {st }}$ CENTURY Vol. 75 , No. 4, 2017

390

demonstrates that the EDPI approach which allows students to make connections and organize their daily life experiences with the environment could enrich their scientific imagination beginning from the stage of association.

The EDPI outreach program not only enabled students to specify problems correlating with life experiences but also provided an avenue for them to propose solutions to a universal problem. Notably, the students showed their creativity, ingenuity and enthusiasm to create prototypes that could become solutions to a problem they faced. Students could illustrate the physical features and functions of their creations in forms of wind mills, water mills, water pumps, greenhouse, or water sprinklers etc. Students expressed that the sketching process for ideas or solutions enabled them to envision and organize the physical features and functions of their creations. This process has helped students to foster the dynamic adjustment process of their scientific imagination.

This program tailored according to the engineering design process also managed to cultivate an environment that encouraged students to engage in sketching detailed drafts of their creations and illustrating details for their choice of material, and techniques for assembling parts. Students conceptualized, organized and formulated their final drafts, even if they varied in detail, focus, characteristics, choice of material, and assembly techniques for assembling parts. New ideas were generated by improving their sketches through the process of trial and error. Ho et al. (2013) similarly highlighted one's ability to make use of the process of trial and error in imaginative activities. Despite several difficulties encountered during the activities, students were able to make improvisations towards their sketches and formulate better prototypes through group effort and guidance from facilitators. This research demonstrated that the virtual implementation process in the scientific imagination of the students was inculcated among them by consolidating students' conceptualization, organization, and formulation of ideas via group members and facilitators' guidance, and the process of trial and error.

However, students showed no significance change in their overall mean scores in the brainstorming component of the initiation stage. In other words, brainstorming did not produce more or better ideas in comparison to the same number of individuals who worked independently in regards to specifying problems. Numerous studies have provided insight about group brainstorming; more and better ideas would be generated if they are provided with enough time to extend their effort (Basadur \& Thompson, 1986; Parnes, 1961; Watson, Michaelsen, \& Sharp, 1991). This statement would clarify the reason as to why the participants had limited ideas as a group because they have also pointed out the amount of time devoted to the STEM activities was insufficient.

The students' scientific imagination, according to the findings, is mainly based upon their own observations and experiences about events in their daily surroundings and environment. The most common source for ideas presented by the students $(90 \%)$ originated from their realization of the need to solve real life personal and familial encounters with irrigation problems in their paddy fields and the adverse effects of El Niño. Previous research (Lindqvist, 2003; Pelaprat \& Cole, 2011; Vygotsky, 2004) also confirms that an individual's daily life experience is the source of imagination. Besides that, social experiences derived from interactions with information-based technology, internet-based information, and group discussions were also needed for students to generate novel ideas. Vygotsky (2004) similarly opined that an imaginative creation draws upon and combines different elements of prior experiences and social experiences with other people.

While the students described many sources as the catalyst for their imagination, they also voiced out several issues during the process of thinking for new ideas. The most mentioned challenging aspect in the program was insufficient scientific and technical knowledge, which was evident from some impractical and irrelevant answers given in the pre-test. Students overcame this deficiency by combining or comparing group members' ideas and getting help from the facilitators in forms of clues, ideas or tips. A previous study (Siew, Amir, \& Chong, 2015) also asserted that sufficient scientific knowledge was an aspect that determined success in STEM activities. The research highlighted that students who are equipped with sufficient scientific and 
technical knowledge would be able to think of lots of possible practical and relevant creations in the real world. Thus adequate classroom opportunities to strengthen students' scientific and technical knowledge is a critical matter and should be enforced by educators.

The final prototypes produced by the student groups were mostly different from the original ideas. This was a direct result of the students' efforts to combine and refine their creations through the iterative thinking process and trial and error. Ho et al. (2013) similarly believe that individuals use imagination to create new inventions to improve life through the process of constant thinking and trial and error. In tandem, a previous study by Siew, Goh and Sulaiman (2016) has affirmed that the integration of STEM in an engineering design process enabled students to organize their thoughts to choose the best possible solution for their prototype using related scientific concepts.

\section{Conclusions}

This research was successfully conducted and investigated the positive impacts of the EDPI outreach program on Grade 10 rural school students (16 years old) by guiding them through a series of processes to foster their scientific imagination. The research findings reveal statistically significant gains in the students' initiation (association), dynamic adjustment, and virtual implementation stage after participating in the EDPI outreach program.

In summary, the findings conclude that students require both social or environmental interactions (e.g.: occurrences in surroundings, exposure to information-based technology and internet-based information, facilitators guidance and support, and group discussions) and personal daily life experiences in order to progress from the initiation stage to the virtual implementation stage. Under the facilitation of the EDPI approach, students were able to formulate concise ideas capable of solving problems associated with the STEM activities, in spite of insufficient scientific and technical knowledge. The EDPI approach can create a supportive environment for fostering scientific imagination among rural secondary school students. By nurturing students' scientific imagination, science educators can prepare students to become better creative thinkers and problem-solvers who have the necessary abilities and skills to address problems and issues faced on an everyday level in new and innovative ways. This research has therefore highlighted the pivotal role of applying integrated approaches such as the EDPI approach to propel students' scientific imagination to greater heights in line with the needs of the country in this $21^{\text {st }}$ century.

This study embraces the usability of an EDPI approach as a reference model for scholars, academicians and educators who are driven to develop a similar learning process for fostering scientific creativity and this study also proposes that the approach can be further upgraded or improved for maximum effectiveness in the future.

\section{Acknowledgements}

The research was supported by the University of Malaysia Sabah (UMS), Malaysia under Grant No. SBK0296-SSI-2016. Any opinions, viewpoints, findings, conclusions, suggests, or recommendations expressed here are the author's and do not necessarily reflect the views of the University of Malaysia Sabah, Malaysia.

\section{References}

Abdul Majid, N., Nordin, A. R., \& Kamarodzan, N. (2015). Penjanaan idea kreatiflukisan kanak-kanak menerusi kaedah imitasi [Creative idea generation in child painting through imitation method]. Jurnal Penyelidikan Dedikasi, 9, 124-136.

Babbie, E. R. (2001). The practice of social research. $8^{\text {th }}$ eds. Wadsworth Publishing Group: Belmont.

Basadur, M., \& Thompson, R. (1986). Usefulness of the ideation principle of extended effort in real world professional and managerial creative problem solving. Journal of Creative Behavior, 20 (212), $23-34$. 
Nyet Moi SIEW. Fostering students' scientific imagination in STEM through an engineering design process

PROBLEMS

OF EDUCATION

IN THE $21^{\text {st }}$ CENTURY Vol. 75, No. 4, 2017

392

Bond, T. G. \& Fox, C. M. (2015). Applying the Rasch model: Fundamental measurement in the human sciences. $3^{\text {rd }}$ eds. New York: Routledge.

Creswell, J. W. (2003). Research design: Qualitative, quantitative and mixed approaches. $2^{\text {nd }}$ eds. Los Angeles: Sage Publication.

Creswell, J. W. (2012). Educational research: Planning, conducting, and evaluating quantitative and qualitative research. $4^{\text {th }}$ eds. Boston: Pearson.

Farmer, C., Allen, D. T., Berland, L. K., Crawford, R. H., \& Guerra, L. (2012). Engineer your world: An innovative approach to developing a high school engineering design course. Paper presented at the meeting of the American Society for Engineering Education, San Antonio, TX.

Gajdamaschko, N. (2005). Vygotsky on imagination: Why an understanding of the imagination is an important issue for school teachers. Teaching Education, 16(1), 13-22.

Ho, H. C., Wang, C. C., \& Cheng, Y. Y. (2013). Analysis of the scientific imagination process. Thinking Skills and Creativity, 10,68-78.

Householder, D. L., \& Hailey, C. E. (Ed.). (2012). Incorporating engineering design challenges into STEM courses. National Center for Engineering and Technology Education.

Hynes, M., Portsmore, M., Dare, E., Milto, E., Rogers, C., \& Hammer, D. (2011). Infusing engineering design into high school STEM courses. Retrieved from http://ncete.org/flash/pdfs/Infusing Engineering Hynes.pdf.

Joh, A. S., Jaswal, V. K., \& Keen, R. (2011). Imagining a way out of the gravity bias: Preschoolers can visualize solution to a spatial problem. Child Development, 82 (3), 744-750.

Kind, P. M., \& Kind, V. (2007). Creativity in science education: Perspectives and challenges for developing school science. Studies in Science Education, 43 (1), 1-37.

Liang, C., Hsu, Y., Huang, Y., \& Chen, SC. (2012) How learning environments can stimulate student imagination. The Turkish Online Journal of Educational Technology, 11(4), 432-441.

Linacre, J. M. (2003). Dimensionality: contrasts and variances help for Winsteps Rasch Measurement software. Retrieved from http://www.winsteps.com/winman/principalcomponents.htm.

Linacre, J. M., \& Wright, B. D. (2012). A User's Guide to WINSTEPS Ministeps Rasch Model Computer Programs. Chicago: Mesa Press.

Lindqvist, G. (2003). Vygotsky's theory of creativity. Creativity Research Journal, 15 (2-3), 245-251.

Lottero-Perdue, P. S. (2015). Running head: The engineering design process, responses to failure, Towson University. Presented at NARST 2015.

Massachusetts Department of Education. (2006). Massachusetts science and technology/engineering curriculum framework. Malden, MA: Author. Retrieved from http://www.doe.mass.edu/ frameworks/scitech/1006.pdf

McCormack, A. J. (2010). Imagine and invent: Create a great future. The Science Teacher, 77(6), 8-9.

Ministry of Education Malaysia. (2014a). STEM education: policies and prospects toward achieving international standard and meeting national development needs.

Retrieved from http://www.akademisains.gov.my/download/STEM\%20Education_Dr\%20Azian. pdf

Ministry of Education Malaysia. (2014b). Primary School Standard Curriculum. Putrajaya: Curriculum Development Division.

Ministry of Education Malaysia. (2016). Secondary School Standard Curriculum. Putrajaya: Curriculum Development Division.

Neo, M., Neo, K. T. K., \& Tan, H. Y. J. (2012). Applying authentic learning strategies in a multimedia and web learning environment (MWLE): Malaysian students' perspective. TOJET: The Turkish Online Journal of Educational Technology, 11(3), 50-60.

Parnes, S. J. (1961). Effects of extended effort in creative problem solving. Journal of Educational Psychology, 52 (3), 117-122.

Pelaprat, E., \& Cole, M. (2011). Minding the gap: Imagination, creativity and human cognition. Integrative Psychological and Behavioral Science, 45 (4), 397-418.

Policastro, E., \& Gardner, H. (1999). From case studies to robust generalizations: An approach to the study of creativity. In R. J. Sternberg (Eds.), Handbook of creativity (pp. 213-255). New York: Cambridge University Press.

Porter, A., \& Brophy, J. (1988). Synthesis of research on good teaching: Insights from the Work of the Institute for Research on Teaching. Educational Leadership, 45 (8), 74-85.

Robinson, K. (2011). Out of our minds: Learning to be creative. United Kingdom: Capstone Publishing. 
Salleh, S., \& Sailin, R. (2014). Kajian hubungan imaginasi, kreativiti dan idea dalam komunikasi penulisan kreatif. [Relationship between imagination, creativity and ideas in communication creative writing]. E-proceedings of the Conference on Management and Muamalah (CoMM 2014), 26-27 May 2014, Synergizing Knowledge on Management and Muamalah.

Sanders, L., \& Budnik, M.M. (2009). Encouraging scientific imagination in elementary students. Retrieved from https://www.researchgate.net/publication/251238910_ENCOURAGING_ SCIENTIFIC IMAGINATION_IN_ELEMENTARY_STUDENTS

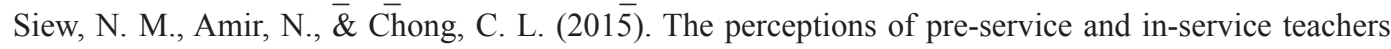 regarding a project-based STEM approach to teaching science. SpringerPlus, 4 (8), 1-20.

Siew, N. M., Goh, H., \& Sulaiman, F. (2016). Integrating STEM in an engineering design process: The learning experience of rural secondary school students in an outreach challenge program. Journal of Baltic Science Education, 15 (4), 477-493.

Vygotsky, L. S. (2004). Imagination and creativity in childhood. Journal of Russian and East European Psychology, 42 (1), 7-97.

Wang, C. C., Ho, H. C., \& Cheng, Y. Y. (2015). Building a learning progression for scientific imagination: A measurement approach. Thinking Skills and Creativity, 17, 1-14.

Weick, K. E. (2006). The role of imagination in the organizing of knowledge. European Journal of Information Systems, 15 (5), 446.

White, A. R. (1990). The language of imagination. Oxford: Blackwell.

Watson, W., Michaelsen, L. K., \& Sharp, W. (1991). Member competence, group interaction, and group decision making: A longitudinal study. Journal of Applied Psychology, 76 (6), 803-809.

Yong, X. H., \& Phang, F. A. (2015). Science and arts streams students' scientific epistemological beliefs. International Education Studies, 8 (13), 88-92. 